\title{
Una mirada a los Hospitales Neogranadinos de la Orden San Juan de Dios desde las visitas-reforma (1774-1777)*
}

por

\author{
Javier Rivera-Sandoval ${ }^{1}$
}

Universidad del Norte, Colombia

\begin{abstract}
Para la segunda mitad del siglo XVIII se hizo evidente la crisis financiera, administrativa y asistencial de los hospitales de la América colonial. Como parte de las políticas de mejoramiento y control de los establecimientos financiados por la Corona española, se implementaron mecanismos de registro que tenían como propósito evaluar la situación por la que estaban atravesando estos centros asistenciales. El presente trabajo reúne la serie documental producida entre 1774 y 1777 por Fray Nicolás de la Concepción Delgado, visitador nombrado para los catorce hospitales de la Orden San Juan de Dios en la provincia de Nueva Granada, territorio que hoy ocupan las repúblicas de Colombia y Panamá. El objetivo principal del trabajo es brindar información sobre la situación que vivian estas instituciones a partir de las descripciones hechas en las visitas-reforma y la relevancia que adquiere para el gobierno peninsular la labor de registrar e inventariar los aspectos de la vida económica y social de los hospitales.
\end{abstract}

Palabras Clave: hospitales; Nuevo Reino de Granada; siglo XVIII; visitas-reforma; Colombia; Panamá.

Cómo CITAR eSte artículo / Citation: Rivera-Sandoval, Javier, "Una mirada a los Hospitales Neogranadinos de la Orden San Juan de Dios desde las visitas-reforma (17741777)", Revista de Indias, LXXVIII/274 (Madrid, 2018): 789-817. https://doi.org/10.3989/ revindias.2018.024.

* Este artículo ofrece parte de los resultados obtenidos por la Beca de Investigación otorgada por el Instituto Colombiano de Antropología e Historia (ICANH) y su programa de apoyo a la investigación en historia colonial, año 2010.

1 jwrivera@uninorte.edu.co, ORCID iD: https://orcid.org/0000-0002-4204-1818. de uso y distribución Creative Commons Reconocimiento 4.0 Internacional (CC BY 4.0). 


\section{INTRODUCCIÓN}

Desde el siglo XVI, las autoridades españolas vieron la necesidad de atender a la población más vulnerable de los poblados establecidos en América y Asia, a través de la fundación de las instituciones hospitalarias. Sin embargo, no hubo claridad en cómo se debían sostener, financiar y administrar estos espacios, lo que generó que los entes gubernamentales discutieran sobre la necesidad de regular la estructura de funcionamiento de estos establecimientos.

Esta situación se acentúo por la insostenibilidad económica que representaba este tipo de obras durante el siglo XVIII, las cuales tenían que acudir a todo tipo de fuentes incluyendo las gubernamentales. Pero la crisis también se refleja en la demora que tomó el proceso de ampliación de la infraestructura y la planta asistencial de los hospitales en América, ocasionada entre otras causas, por las repetidas crisis económicas que enfrentó España durante el período colonial ${ }^{2}$. Sin embargo, se intentan contrarrestar estos problemas, a través del paquete de medidas que los Borbones diseñan para reformar la estructura de los entes institucionales a cargo de la administración de las colonias españolas. En esta dinámica, los hospitales de la Orden San Juan de Dios por ser edificios públicos y estar parcialmente financiados por la Coro$\mathrm{na}^{3}$, son objeto de dicho programa político.

No obstante, el gobierno peninsular no contaba con los mecanismos para hacer un seguimiento al cumplimiento de las constituciones conventuales y al manejo que se les estaba dando a estos centros asistenciales. Se decide aprovechar entonces un instrumento establecido por las mismas órdenes religiosas que era ejecutado periódicamente y que gracias a la organización de su estructura, permitía registrar varios aspectos vinculados con el desempeño público de las instituciones y el comportamiento de los religiosos que estaban a su cargo ${ }^{4}$, este mecanismo se denominaría visitas-reforma.

Este instrumento responde a una serie de intereses socio-políticos y principalmente económicos del gobierno español, que además de velar por la salud pública de sus súbditos, querían conocer el manejo de los dineros que estaban invirtiendo en estos establecimientos. De hecho durante el siglo XVIII, esta preocupación estaba vinculada con la idea de que «la medicina y la salud eran un problema económico» ${ }^{5}$. En este sentido, la reestructuración política y administrativa de la Corona estaba apuntando también a potencializar el apro-

\footnotetext{
2 Lynch, 2009.

3 Agudelo, 1983: 514.

4 Alberro, 2005.

5 Foucault, 1996: 80.
} 
vechamiento de los recursos, incluyendo los humanos, lo que va a atravesar varias esferas de la vida cotidiana, incluyendo la asistencia sanitaria de los ciudadanos $^{6}$. Sin embargo, no se va a lograr establecer un modelo relativamente efectivo hasta bien entrado el siglo XIX ${ }^{7}$. No obstante, el siglo XVIII marcará la pauta para el registro detallado de la información que posteriormente servirá de soporte para el diseño de políticas estatales en relación a cómo se debe manejar la salud y cuál debe ser el propósito de los centros asistenciales. Las visitas-reforma responderán entonces a esa necesidad de conocer cómo funcionan las instituciones hospitalarias, las cuales hacían parte de la red institucional que dependía de la Corona y, cuyo control sobre el orden social y administrativo de esta red estaba debilitado por múltiples procesos.

A pesar de que este período marcó un avance en varios procedimientos para la diagnosis y tratamiento de las enfermedades, incluyendo el redescubrimiento de medicamentos de origen americano que fueron introducidos en la farmacopea ${ }^{8}$, los hospitales seguían siendo instituciones religiosas, donde la regulación de las prácticas y discursos dependía exclusivamente de la Iglesia. De esta forma, la enfermedad y la dolencia aún eran concebidas como instrumentos para la salvación del alma a través del suplicio del cuerpo ${ }^{9}, \mathrm{y}$ los modelos asistenciales estaban asociados con el concepto de caridad dirigida a los pobres. Con este contexto se justifica la necesidad de realizar reformas al interior de los hospitales, teniendo en cuenta además otros aspectos que impulsaron este proceso en la Nueva Granada.

Por ejemplo, se observa un aumento importante de la población en los centros urbanos, causado principalmente por la migración rural a causa de la apertura agrícola y minera ${ }^{10}$, se discute sobre la restringida capacidad de reacción del gobierno peninsular y colonial en enfrentar las olas epidémicas que aquejaron Nueva Granada y las inadecuadas condiciones asistenciales ofrecidas por los hospitales ${ }^{11}$, surge una élite ilustrada preocupada en las condiciones sanitarias de las ciudades y en el rol que debía desempeñar el hospital dentro de una política de salud pública, que además debían participar en la reestructuración de los modelos de la enseñanza y de la práctica médica ${ }^{12}$. Sin

\footnotetext{
6 Alzate Echeverri, 2007.

7 Foucault, 1996; 2003.

8 Frías Nuñez 1992: 27. Nieto Olarte, 2000: 9-20. López Piñero, 2007: 17-23.

9 Rivera, 2014: 198-205.

10 Alzate Echeverri, 2012: 42-43.

11 Ibidem: 43. Frías Núñez, 1994: 84-92.

12 Alzate Echeverri, 2012: 43.
} 
embargo, para implementar los cambios que requerían las instituciones hospitalarias con esta nueva estructura de pensamiento, era necesario evaluar las condiciones en las que estaban los centros asistenciales.

Este artículo se encamina a identificar qué aspectos de las prácticas administrativas y asistenciales ${ }^{13}$ de los hospitales fueron consignados en las visitas-reforma, las cuales corresponden a las particularidades socio-políticas y económicas de los sitios en los cuales se produjeron dichos documentos, pero que fueron ejecutados como instrumento de registro para el programa reformista de los Borbones. Para ello, se tomará como caso de estudio la serie documental producida por el padre Fray Nicolás de la Concepción y Delgado, visitador reformador de la Orden San Juan de Dios para la provincia del Nuevo Reino de Granada entre 1774 y 1777, territorio que hoy conforman las actuales repúblicas de Colombia y Panamá. A partir de estos archivos se tomó información que incluyó variables como las cuentas de ingresos y gastos de cada hospital, que brinda una idea del manejo administrativo que tenían dichas instituciones y otros datos sobre las prácticas que estaban ejecutando.

A pesar de que desde 1611 en las constituciones conventuales de la orden San Juan de Dios se habían establecido las visitas como mecanismo de seguimiento para los hospitales en Indias, solo hasta 1738 se presentan nuevas adiciones que permiten crear una nueva estructura administrativa, en las que se nombran comisarios, como Fray Nicolás de la Concepción y Delgado, quienes tendrían la función de hacer las visitas a las casas y hospitales, redactando informes que serían entregados por ellos o sus secretarios en España, además sancionarían a los sujetos que según su criterio cometieran faltas, velarían por el mantenimiento de sus costumbres y sugerirían reformas en las instituciones a su cargo ${ }^{14}$.

Sin embargo, para los hospitales neogranadinos solo se tiene registro de la serie producida entre 1774 y 1777, sin que se conserve en los archivos consultados documentos similares que hayan sido producidos antes o después de este intervalo de tiempo, a excepción de la visita hecha por Fray Miguel de Isla en 1786 al hospital de Cartagena de Indias ${ }^{15}$, registro que no se refleja para los otros establecimientos neogranadinos, por lo que no brindaba una

13 En este trabajo se abordará como prácticas asistenciales aquellas vinculadas con las labores de atención corporal al enfermo, las cuales no incluyen aquellas de carácter espiritual, que igualmente se ofrecía al interior de estos establecimientos y que configuraron un escenario importantísimo en la lógica funcional de estos hospitales.

14 Agudelo, 1983: 393.

15 Al respecto, se puede consultar un análisis hecho sobre los datos consignados en esta visita en Alzate Echeverri, 2012: 111-116. 
imagen panorámica de la situación de los hospitales en este período. Si bien los tres años en los que se concentra la información recopilada para este trabajo no son suficientes para elaborar una síntesis sobre procesos de cambio, transición o adecuación de los hospitales, permite aproximarnos al momento específico en el que se estaban configurando nuevas ideas alrededor de las prácticas asistenciales, pero al mismo tiempo registrando aspectos de la vida cotidiana en estos establecimientos.

Estos datos se convirtieron en la base para realizar un balance de la inversión hecha por la Corona en estas instituciones, considerando además los datos sobre la nómina de religiosos que atendía los enfermos, el número de pacientes recibidos y fallecidos, las condiciones en que eran atendidos y la distribución espacial de estos edificios. Estas variables brindan un panorama general sobre la forma en que funcionaban dichos hospitales y qué aspectos fueron registrados en las visitas-reforma.

\section{LAS VISITAS-REFORMA COMO INSTRUMENTO DE LAS REFORMAS BORBÓNICAS}

Para el siglo XVIII las academias científicas europeas, principalmente en Francia e Inglaterra, estaban adelantando visitas a hospitales, lazaretos y prisiones, en las que recogían datos a través de encuestas sistemáticas que permitían la comparación de los establecimientos y de esta manera diseñar programas de reforma hospitalaria ${ }^{16}$. En Iberoamérica, con el ascenso de Carlos III se da un interés similar que con una racionalidad económica pretende organizar con mayor eficiencia los recursos, apoyado por un discurso científico que tardará en ser asimilado. Esto se dará gracias a las consecuencias de procesos como la contrarreforma y el programa político de los Austrias, que mantuvieron a España y sus colonias al margen de la escena científica moderna, lo generó un evidente atraso en las maneras de pensar y actuar ${ }^{17}$. De esta forma, los hospitales seguirían siendo vistos por mucho tiempo como escenarios para el alivio espiritual y para recibir la muerte, y no como espacios para curar enfermos.

No obstante, para implementar la fase de registro la Corona aprovechará un mecanismo de control interno que tenían las órdenes religiosas denominadas visitas-reforma. Sin embargo, la estrategia de recopilación de datos se verá en otros contextos a lo largo de la segunda mitad del siglo XVIII. A partir de estas estrategias de recolección informativa la casa de los Borbones pretendía

\footnotetext{
16 Foucalut, 1996: 107. Risse, 1999.

17 Martínez Zulaica, 1973. Albarracín Teulán, 1989: 31-34. Romero, 1997.
} 
impulsar cambios políticos, económicos y sociales en todos sus territorios, con una clara influencia ideológica del proceso de Ilustración, que permitió en cierta medida la utilización de nuevos discursos argumentativos producidos por la Ciencia, que se utilizaron para justificar las modificaciones que la monarquía proponía realizar.

Al respecto, Alzate señala que las reformas borbónicas constituyen un proyecto para civilizar las costumbres, a través de la creación de sujetos «sanos, obedientes y productivos $\gg{ }^{18}$. En teoría, estos individuos serían capaces de reproducir ese nuevo modelo de comportamiento que atravesaría todas las esferas de la vida cotidiana de quienes habitaban los poblados bajo el dominio español. Para ello, se diseñaron una serie de mecanismos de control y vigilancia que buscaban, por un lado, perseguir aquellas prácticas que atentaban con el modelo moralizador y civilizador impuesto por la Corona y, por el otro, ejecutar una reforma que permitiera introducir los nuevos ideales de la sociedad moderna, para ello se utilizó el discurso científico, político y educativo ${ }^{19}$. Sin embargo, este proceso debía partir de una base empírica que sustentará el diseño de estas nuevas políticas con un discurso legitimado por la academia.

De esta manera, las reformas borbónicas empezarán a gestar cambios en relación a las estructuras de pensamiento y conducta, que incluyen aspectos como el manejo de los espacios públicos incluyendo: hospitales, hospicios, cementerios, calles, etc. ${ }^{20}$ De igual forma, las instituciones civiles empezaron a configurar las bases para las políticas de salud pública e higiene, las cuales nacen de los dispositivos organizados alrededor de las figuras de ornato y policía.

Una de las herramientas empleadas por los entes gubernamentales adscritos a la Corona, fue la ejecución del «orden» en diferentes niveles, que se instaura a través de prácticas discursivas que son históricamente particulares a los procesos sociales. En este caso, se vinculará con el interés de la elite americana del siglo XVIII por moralizar y civilizar sus poblaciones, buscando seguir el modelo europeo y empleando conceptos como progreso, salud pública, urbanidad, entre otros ${ }^{21}$.

Fue así como médicos, científicos, funcionarios públicos y sacerdotes sirvieron de intermediarios y de promotores de estas ideas, lo que más adelante

\footnotetext{
18 Alzate Echeverri, 2007: 12.

19 Idem.

20 Alzate Echeverri, 2007; 2012. Rivera, 2004. Restrepo Zea, 2006.

21 Alzate Echeverri, 2007; 2012.
} 
se traduciría en los mecanismos empleados para acercar a las clases populares al conocimiento científico, a través de la educación ${ }^{22}$.

La ciencia justificó el impulso que la Ilustración española le dio a las expediciones a lo largo y ancho del territorio americano, en búsqueda de alternativas que se adecuaran a los intereses económicos del imperio. Es así como surge un proceso de identificación, clasificación, recolección, reordenación y apropiación de los recursos que habían en el nuevo mundo, tal vez el ejemplo más claro fue la expedición botánica que marcada evidentemente por las ideas propuestas por científicos como Lamarck y Linneo, junto con la inspección efectuada a los saberes locales, le otorgó un nuevo significado a la movilidad de las fronteras entre el centro y la periferia, que finalmente desencadenaron en el «descubrimiento» y control de estas especies vegetales en función de los intereses del estado español, donde la ciencia se empleó como mecanismo de poder ${ }^{23}$. Alzate señala que este dispositivo de registro minucioso se aplicó en áreas como la geografía, la historia, el clima y la demografía, donde se generaban un conjunto de datos concretos y medibles, empleados en el desarrollo de nuevos conocimientos en distintas áreas que no siempre fueron aprovechados por el gobierno ${ }^{24}$.

Ese instrumento de registro e inspección es lo que se aplicará en el caso de las visitas-reforma hechas en los hospitales de San Juan de Dios ${ }^{25}$. No obstante, como se mencionó arriba, las visitas habían sido contempladas por las instituciones eclesiásticas como un mecanismo de control de su práctica religiosa, financiera y disciplinar ${ }^{26}$, pero posteriormente es empleado por las autoridades civiles. En el caso de las visitas hospitalarias realizadas entre 1774 y 1777 , se puede hablar que tuvieron un carácter evaluativo que estaba articulado con las directrices del proyecto modernizador de la Corona, limitando el poder que la Iglesia había adquirido durante casi tres siglos en diferentes ámbitos económicos y sociales de la sociedad colonial, con modelos conside-

22 Barrancos, 1996: 16-18.

23 Este ha sido un tema abordado amplísimamente por varios investigadores de la historia de la Ciencia en Colombia, véase entre otros a Martínez Zulaica, 1973. Pérez Arbeláez, 1983. Hernández de Alba, 1986. Frías Nuñez, 1994. Andrade González, 1997. Nieto Olarte, 2000. Amaya, 2005. San Pio Aladrén, 2008. Díaz Piedrahita, 2009: 7-12. Amaya y Torres, 2013.

24 Alzate Echeverri, 2007: 25.

25 En el Diccionario de Autoridades de 1739 se define «visita» como «el reconocimiento, ù informe, que se hace en los Oficios públicos de los instrumentos, y géneros, que respectivamente tocan à cada uno, para vér si están fieles, ò segun ley, ù ordenanza», Diccionario de la Real Academia Española, 1739, consulta hecha el 16 de febrero de 2016 en: http://web.frl. es/DA.html.

${ }^{26}$ Alzate Echeverri, 2012: 110. 
rados poco efectivos y anticuados, que debían ser corregidos desde un punto de vista administrativo ${ }^{27}$.

En este sentido, la estructura de las visitas-reforma fue aprovechada para inventariar, describir, clasificar y documentar todo lo relacionado con las actividades, cuentas, sujetos, espacios y elementos que tuvieran que ver con estos establecimientos. De esta forma, a partir de la producción de un modelo de registro, se intentó construir una base documental que justificara la formulación de nuevas políticas administrativas y sanitarias, vinculadas con espacios y sujetos que empiezan a verse como punto de origen de problemas colectivos.

\section{LOS HOSPITALES NEOGRANADINOS PARA EL SIGLO XVIII}

Según el capítulo 30 de las constituciones conventuales del San Juan de Dios de 1738 se establecía la manera en que los comisarios generales debían realizar las visitas en sus casas de España y de las Indias, velando por que se cumpliera la «cura» espiritual a los «pobres-enfermos», a quienes debían prestar su servicio ${ }^{28}$.

Siguiendo estas directrices, se nombró al padre Fray Nicolás de la Concepción y Delgado, como visitador general para efectuar las visitas en los 14 hospitales administrados por los religiosos de la orden San Juan de Dios en el Virreinato de la Nueva Granada entre 1774 y 1777. Asimismo, se nombró a Fray Pedro de Elizalde como su secretario quien lo apoyaba en estas labores.

Además de estos dos religiosos, el padre Fray Fernando Gaviola actuó como segundo visitador reformador de la orden religiosa ${ }^{29}$, quien se encargó de efectuar la visita al Hospital de la ciudad de Cali junto con el padre Fray Diego García como secretario ${ }^{30}$. Las demás visitas referenciadas en este trabajo fueron realizadas por Fray Nicolás de la Concepción y Delgado y Fray Pedro de Elizalde, el primero de ellos nombrado en 1773 como primer visitador de las provincias correspondientes a las órdenes religiosas de San Francisco, San Agustín, Santo Domingo, La Merced y San Juan de Dios, en re-

27 Idem.

28 Agudelo, 1983: 390.

29 Patente principal para el segundo visitador reformador de la Provincia de Tierra Firme, Madrid, 29 de mayo de 1771, Archivo General de la Nación, Bogotá (en adelante AGN), Miscelánea 140, f. 583v.

30 Actas de la visita de Fray Fernando Gaviola practicada en el convento hospital de San Juan de Dios de Cali, Cali, enero de 1775, AGN, Conventos 54, ff. 513r-556v. 


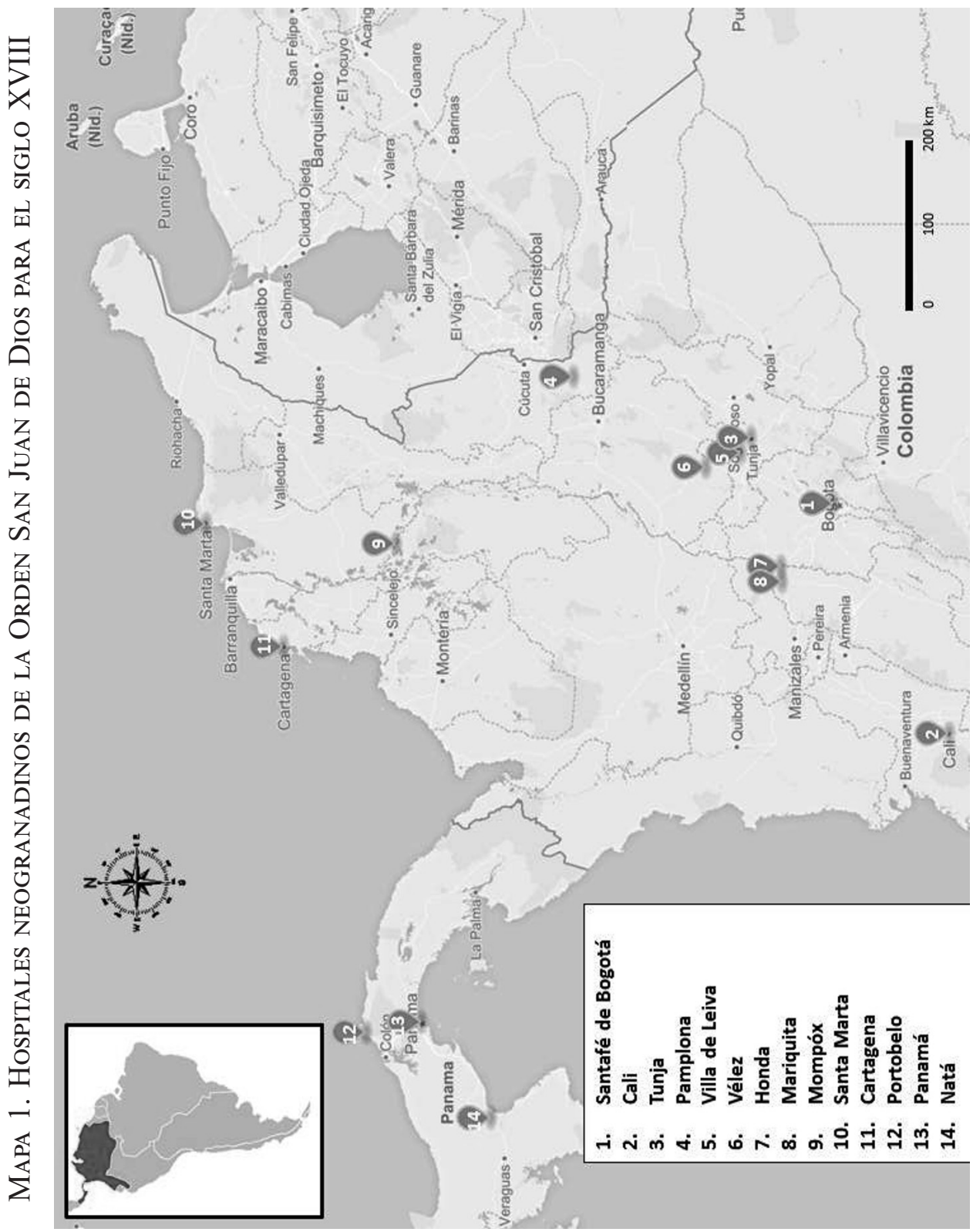


emplazo de Fray Francisco de Soto ${ }^{31}$. A continuación se relaciona los hospitales de la orden San de Dios que fueron visitados entre 1774 y 1777, y que hacían parte del Virreinato de la Nueva Granada:

TABla 1. Relación de los HosPitales NeOGRANAdinos Visitados ENTRE 1774 Y 1777

\begin{tabular}{|l|l|l|}
\hline \multicolumn{1}{|c|}{ Ciudad } & \multicolumn{1}{c|}{ Nombre del Hospital } & \multicolumn{1}{c|}{ Fecha de la Visita } \\
\hline Santafé de Bogotá & Hospital de Jesús, María y José & Abril de 1774 \\
\hline Cali & Hospital de Nuestra Señora de Chiquinquirá & Enero de 1775 \\
\hline Tunja & Hospital de Nuestra Señora de la Concepción & Septiembre de 1776 \\
\hline Pamplona & Hospital de la Señora Santa Ana & Septiembre de 1776 \\
\hline Villa de Leiva & Hospital de Nuestra Señora de Monserrate & Octubre de 1776 \\
\hline Vélez & $\begin{array}{l}\text { Hospital del Sagrado Orden de San Juan } \\
\text { de Dios }\end{array}$ & Octubre de 1776 \\
\hline Honda & Hospital de San Rafael & Diciembre de 1776 \\
\hline Mariquita & Hospital de San José & Diciembre de 1776 \\
\hline Mompóx & Hospital de San Juan Bautista & Enero de 1777 \\
\hline Santa Marta & Hospital de San Rafael & Febrero de 1777 \\
\hline Cartagena & Hospital de San Sebastián & Marzo de 1777 \\
\hline Portobelo (Panamá) & Hospital de San Sebastián & Mayo de 1777 \\
\hline Panamá & Hospital de San Sebastián & Julio de 1777 \\
\hline Natá (Panamá) & Hospital de la Santísima Trinidad & Agosto de 1777 \\
\hline
\end{tabular}

La celebración de las visitas-reforma era un hecho solemne, que debía seguir un protocolo de ejecución y el que obviamente estaba cargado de una serie de prácticas de corte ritual que se efectuaban por lo general en la sala capitular del convento, en presencia de todos los religiosos que tuvieran voz y voto, por ejemplo en el testimonio de lo adelantado en Natá se menciona lo siguiente:

31 El Secretario del Consejo envía un despacho remisorio de duplicados de patentes expedidas por el vicario general de San Juan de Dios, en que se nombra por Visitador de la congregación a Fray Nicolás de la Concepción y Delgado, Granada, 17 de marzo de 1773, AGN, Miscelánea 140, f. 603r. 
Decimos que habiendo llegado a este santo hospital de la Santísima Trinidad del orden de nuestro padre San Juan de Dios de la ciudad de Nata, y hecho convocar a son de campana, según lo hemos de uso y costumbre de esta venerable comunidad en la celda prioral que sirve de sala capitular; y juntos en ella todos los religiosos e invocando ante todas cosas del Divino Espíritu Santo, mando su reverendísima al Reverendo Padre Fray Pedro Elizande secretario reformador leer las dos patentes pequeñas y haciendo una breve exhortación al cumplimiento de nuestro sagrado instituto santo temor de Dios y mayor desempeño de las obligaciones en que como religiosos nos hallamos constituidos para estar prontos y preparados a esta visita reforma ${ }^{32}$.

Evidentemente estas prácticas se relacionan con la función religiosa que cumplen estas instituciones, donde prevalecía mucho más la asistencia espiritual a la corporal. De igual forma, todas las actividades del Hospital estaban guiadas por el ejercicio de la oración, práctica realizada en la mayoría de los espacios del Claustro en los que se adecuaban altares que en ocasiones también eran empleados para los oficios litúrgicos. Por ejemplo, en la sala capitular, la sala de profundis (ubicada junto al refectorio), la sacristía y las enfermerías tenían estos elementos que al mismo tiempo sacralizaban el espacio.

No obstante, uno de los propósitos que tenía la ejecución de estas visitas-reforma hacia finales del siglo XVIII, contemplaba temas menos espirituales y más cuando se trataba de evaluar las actividades de las obras que financiaba la Corona, incluidos los hospitales, que en función de las disposiciones de la casa de los Borbones se pretendía minimizar los gastos y justificar todo el dinero invertido.

\section{AproXimación a La ECONOMÍA hoSPITALARIA EN NuEva Granada}

Después de realizar los respectivos oficios religiosos, el siguiente procedimiento que se seguía en las visitas-reforma, era la entrega que los priores de cada convento hacían de los libros de cuentas, en los que se incluían los gastos y recibos, además de los anexos en que se registraban otros asuntos administrativos y financieros del hospital. En el caso de los 14 hospitales de la orden San Juan de Dios en Nueva Granada se reportaron las siguientes cuentas:

32 Actas de las reformas que introdujo el padre visitador en el convento hospital de su comunidad en Nata, Panamá, agosto de 1777, AGN, Conventos 16, f. 1001r. 


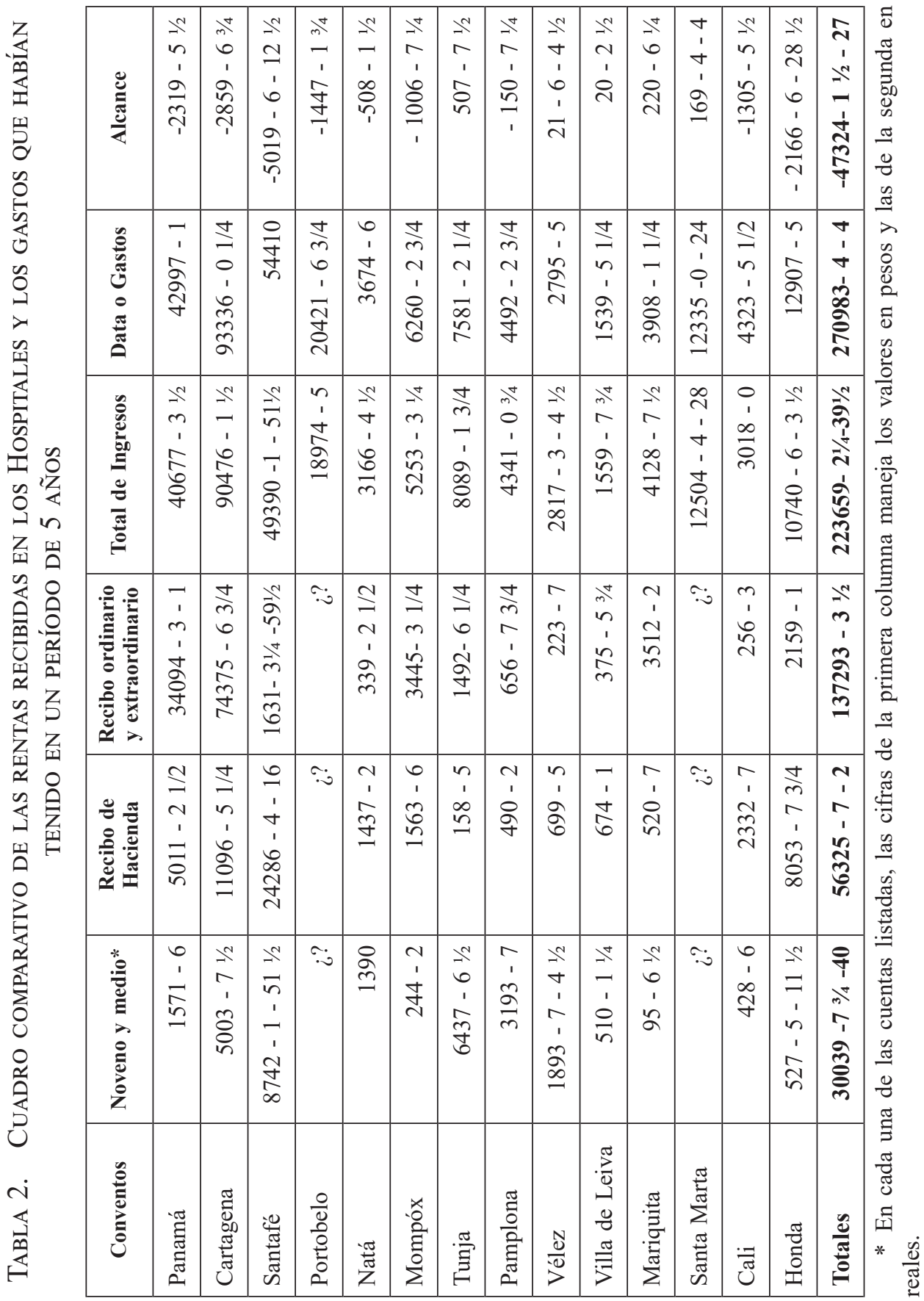


Con los datos presentados en la tabla $2^{33}$, se deduce que solamente los hospitales de Tunja, Mariquita, Santa Marta, Vélez y Villa de Leyva estaban generando un margen de ganancia entre los ingresos y los gastos que manejan dichas instituciones. No obstante, estos 5 hospitales dependían de las arcas reales para mantenerse, rubro que corresponde en promedio al $76 \%$ de todo lo que reciben como ingresos, aunque en el caso de Mariquita cerca del $42,32 \%$ viene del cabildo que se considerarían igualmente como fondos gubernamentales y solo en la visita del hospital de Santa Marta no se hace claridad sobre el origen de sus rentas, pero es muy probable que tenga un comportamiento financiero similar.

De igual forma, se observa que los ingresos de los otros 6 hospitales provenían en su mayoría del erario, representado en el recibo de hacienda y por el diezmo conocido como noveno y medio, rubro que equivalía al $8,2 \%$ del total del diezmo recolectado por el obispado y el cual era proporcionado por

33 La información consignada en las tablas 2, 3 y 4, recopila los datos obtenidos en las siguientes fuentes documentales: Expedientes sobre la visita y reforma de la religión de San Juan de Dios en Lima, Lima, octubre de 1776, Archivo General de Indias, Sevilla (en adelante AGI), Indiferente General 3078. Actas de las reformas que introdujo el padre visitador en el convento hospital de su comunidad en Nata, Panamá. Natá, agosto de 1777, AGN, Conventos 16, ff. 999-1012.Disposiciones dictadas por Fray Nicolás de la Concepción Delgado, en su carácter de visitador de la orden de San Juan de Dios, respecto de asuntos fiscales y espirituales de ella, Santafé, 1774, AGN, Conventos 29, ff. 104-144. Documentos referentes a la visita que practicara Fray Nicolás de la Concepción Delgado, a los establecimientos de los religiosos de San Juan de Dios, en Portobelo y las disposiciones que dictara en orden a asuntos fiscales y espirituales de ellos, Portobelo, mayo de 1777, AGN, Conventos 29, ff. $207-$ 220. Testimonio de la visita practicada en el hospital convento de Vélez, por Fray Nicolás de la Concepción Delgado, en su carácter de visitador de los religiosos de San Juan de Dios de Nueva Granada, Vélez, octubre de 1776, AGN, Conventos 29, ff. 270-283.Testimonio de las reformas introducidas en el convento hospital de San Juan de Dios de Cartagena, por el visitador y asuntos fiscales del mismo establecimiento, Cartagena, marzo de 1777, AGN, Conventos 34, ff. 587-611. Documentos de la visita fiscal de Fray Nicolás de la Concepción Delgado, al convento hospital de San Juan de Dios de Santa Marta, Santa Marta, febrero de 1777, AGN, Conventos 36, ff. 292-310. Documentos de lo actuado por Fray Nicolás de la Concepción Delgado, como visitador de la orden de San Juan de Dios en Panamá, Panamá, julio de 1777, AGN, Conventos 52, ff. 928-961. Actas de la visita de Fray Nicolás de la Concepción Delgado, religioso de San Juan de Dios y visitador reformador de su orden, de la visita practicada en el hospital de Honda, Honda, diciembre de 1776, AGN, Negocios Exteriores 6, ff. 630-646. Nicolás de la Concepción y Delgado, religioso de San Juan de Dios: Testimonio de la vista fiscal que practicó en el Hospital de San Juan Bautista de la Villa de Mompós, Mompox, enero de 1777, AGI, Caciques e Indios 35, ff. 671-685. Nicolás de la Concepción y Delgado, visitador de la orden de San Juan de Dios, reformas que introduce en el convento de Mariquita, Mariquita, diciembre de 1776, AGN, Historia Eclesiástica 3, ff. 193-206. 
la Corona con el objetivo de apoyar la construcción y mantenimiento de iglesias y hospitales ${ }^{34}$. Como se ve en la tabla 2, los hospitales de Vélez $(67,22 \%)$, Pamplona $(73,57 \%)$ y Tunja $(79,58 \%)$ son las que mayor cantidad de dinero reciben por concepto de noveno y medio en comparación con sus otras rentas. Por otro lado, por concepto de recibo de hacienda las instituciones que más recibieron dinero fueron Cali $(77,29 \%)$ y Honda $(74,98 \%)$, seguidas de lejos por Santa Fe $(49,17 \%)$.

Además de estas entradas, el gobierno español destinó adicionalmente dos rubros que se les asignó a unos pocos establecimientos. En primera medida está el principal de dos mil ducados y arriendo de estancia que la Corona destinaba como limosna anual al Hospital de Portobelo, el cual equivalía al $70,48 \%$ del total de los ingresos de esta institución, cifra que fue adjudicada desde la fundación de este centro asistencial a principios del siglo XVII ${ }^{35}$. Asimismo, este hospital junto con los de Panamá y Cartagena recibían por concepto de media soldada de embarcaciones, un porcentaje de lo que los navíos pagaban en estas zonas portuarias, no obstante esta partida apenas cubría entre el 0,65 y 2,06\% del total de dineros que entraban a las arcas de estos hospitales.

Pero otro panorama era el que vivían los hospitales de Mompóx, Cartagena y Panamá, ya que los principales ingresos que entraban a sus arcas provenían del dinero obtenido en limosnas, censos, capellanías, subsidios, arriendo de propiedades, oficios religiosos (misas y entierros), venta de productos de botica, intereses de capital y prestación de servicio a los cuerpos de armada y esclavos de la Corona, que en este cuadro estaría bajo la categoría de recibo ordinario y extraordinario y, que del total de ingresos en todos los hospitales corresponden al $65.58 \%$ para Mompóx, el $82,20 \%$ para Cartagena y el $83,81 \%$ para Panamá. Sin embargo, el capital se hacía escaso para solventar los gastos operativos de dichas instituciones, de hecho Cartagena y Panamá junto con Santafé, fueron los establecimientos hospitalarios con mayor endeudamiento en la Nueva Granada y a su vez los que más gastaron. Esto puede explicarse en el gran número de habitantes que albergaban estas tres ciudades, que a excepción de Santafé, representaba una activación de las rentas de los hospitales representadas en alquileres, ventas, prestación de servicios, etc. Por otro lado, estaba la posibilidad de adquirir mayor número de limosnas y donaciones provenientes de sus pobladores, siendo Santafé la capital del Virrei-

\footnotetext{
34 Cruz-Coke, 1995: 95.

35 Que el hospital de Portobelo se podrá acomodar de la manera que el presidente de la Audiencia de Panamá lo escribe, Madrid, 28 de agosto de 1606, AGI, Panamá 1, n. 214.
} 
nato y, Cartagena y Panamá los principales puertos sobre el Caribe y el Pacífico respectivamente, situación que se manifiesta en sus ingresos.

No obstante, es posible que la baja proporción en la cifra que tienen las limosnas en el total de los ingresos de los hospitales, respondan al cambio que sufrió la idea de «pobre» a partir de la Ilustración. Desde el siglo XVI, los hospitales trabajaban según los postulados cristianos de personajes como San Pablo quienes hacen claras referencias al amor al prójimo y una reiterada relación entre el cuerpo enfermo y el cuerpo pobre con Cristo, despertando en los feligreses el deseo de cooperar con estas iniciativas misericordiosas ${ }^{36}$. Muchos personajes de la élite financiaron gran parte de estas obras, ya que consideraban una forma de ejercer la caridad cristiana y de perpetuar sus respectivas imágenes como almas piadosas y caritativas, incluso sirviendo y atendiendo a los enfermos dentro de los hospitales ${ }^{37}$. Posteriormente se cuestiona quienes son realmente pobres, además de cómo se debían tratar y quienes debían hacerlo. Esta nueva relación con la representación del pobre, pudo haber generado una disminución en los aportes hechos a las limosnas, que poco a poco se vieron desplazadas por las cesiones que se hacían a los familiares.

Esta nueva situación financiera tuvo un impacto en los gastos operativos de los hospitales, los cuales estaban representados principalmente en la compra de medicamentos y alimentos, vestuario para enfermos y religiosos, obras de reparación del edificio, pago de salarios, gastos en misas y fiestas, entre otros. Haciendo una comparación entre las rentas y los gastos de cada uno de los establecimientos asistenciales, las instituciones que más gastaron proporcionalmente con sus ingresos fueron Cali (143,26\%), Honda (120,17\%), Mompóx $(119,16 \%)$ y Natá $(116,04 \%)$, y los que menos gastaron Tunja $(93,64 \%)$, Mariquita $(94,65 \%)$, Santa Marta $(98,64 \%)$ y Villa de Leyva $(98,69 \%)$. Como se ve en estas cifras, el margen de ganancia en los pocos hospitales que lo tenían era muy bajo, lo que refleja la difícil situación financiera y administrativa de estos establecimientos ${ }^{38}$.

Sin embargo, los religiosos de la orden seguían recorriendo las calles de los poblados donde estaban asentados sus conventos, pidiendo las limosnas que ayudarían a solventar parte de los gastos de estas instituciones. Estos aportes evidentemente se hicieron escasos y aún más con los repetidos problemas con las cosechas, las epidemias y las constantes reformas en los im-

\footnotetext{
36 Risse, 1999: 234. Alzate Echeverri, 2002: 51. Gelis, 2005: 53. Alberro, 2005: 234.

37 Romero, 1997: 190. Ortíz Quesada, 2000: 16.

38 Para el caso de Cartagena de Indias se puede consultar el trabajo de Solano Alonso, 2005
} 
puestos aplicados por el gobierno español. Es claro que la Corona se preocupó por la inversión hecha en estas instituciones y en el manejo financiero de las mismas, haciendo un fuerte control sobre el capital y el manejo de los fondos que tenían, a través del instrumento de las visitas-reforma, que registró de manera detallada todos estos aspectos presupuestales.

\section{LAS PRÁCTICAS ASISTENCIALES EN LOS HOSPITALES NEOGRANADINOS}

Además de administrar el hospital, los Juaninos tenían que prestar la asistencia médica y espiritual, pedir limosna y hacer su vida conventual. De hecho, estas dos últimas tareas fueron puntos de discusión en las visitas hechas a los hospitales, en las cuales se cuestionaba la relajación de los religiosos en sus funciones ${ }^{39}$.

Este tema era abordado dentro de la estructura formal de las visitas-reforma, para ello se invitaba a todos los religiosos involucrados con las labores del establecimiento asistencial a no salir del claustro del hospital sin el permiso y bendición del visitador reformador y, a estar preparados al juramento y declaración que se les iba a hacer respecto a si:

... ha observado el culto divino con la frecuencia de santos sacramentos y ejercicios espirituales, según lo disponen nuestras sagradas constituciones, si se ha cometido defecto contra nuestro caritativo instituto, si la administración de caudales, así por el superior como por los demás a cuyo cargo esta, se hace con rectitud y fidelidad, si se ha quebrantado alguno de los votos que profesamos y si se observan las constituciones de la religión, y ordenanzas generales, como también de otra cualesquiera cosa que deba manifestarse ${ }^{40}$.

Aquí nuevamente se evidencian los pilares conceptuales y filosóficos bajo los cuales estas instituciones fueron concebidas, se resalta la importancia de los denominados ejercicios espirituales y el servicio de los sacramentos a quienes llegan a sus puertas. Para poder llevar a cabo este tipo de iniciativas era imprescindible contar con los suficientes religiosos que apoyaran las labores asistenciales (espirituales y corporales). Por esta razón, era frecuente encontrar hermanos con conocimientos en medicina, cirugía, enfermería y farmacéutica, aunque personal secular cumplía para muchas de estas tareas.

\footnotetext{
39 Alberro, 2005: 240. Alzate Echeverri, 2012: 112-115.

40 Disposiciones dictadas por Fray Nicolás de la Concepción Delgado, en su carácter de visitador de la orden de San Juan de Dios, respecto de asuntos fiscales y espirituales de ella, Santafé, 1774, AGN, Conventos 29, ff. 110r-110v.
} 
En los hospitales de la Nueva Granada al momento de efectuarse las visitas-reforma se encontró con una nómina de personal, que a los ojos del visitador había que modificar en función del número de enfermos que se estaban atendiendo. Esta situación al parecer fue común en las demás provincias de ultramar, ya que para la Corona era preciso controlar la cantidad de religiosos en cada convento.

En el reporte que hace el visitador general, aparece una relación de los enfermos curados y fallecidos en los 14 hospitales de la Nueva Granada en los últimos cinco años a su visita, acompañada del respectivo registro de la nómina de religiosos para cada uno de los establecimientos asistenciales.

En la tabla 3, se observa que en gran parte de los hospitales neogranadinos había un bajo número de religiosos, exceptuando Cartagena y Santa Fe, los cuales también servían como noviciados para la Orden, lo que aumenta considerablemente el número de miembros para estos hospitales. Al respecto, se puede mencionar que 6 de los 23 religiosos registrados en Cartagena y 12 de los 41 en Santa Fe son novicios de aprobación, el tercer hospital con mayor

TABLA 3. RELACIÓN DE ENFERMOS, FALLECIDOS Y RELIGIOSOS QUE HUBO EN LOS HOSPITALES EN EL PERÍODO REGISTRADO POR LAS VISITAS

\begin{tabular}{|l|r|r|r|r|r|r|}
\hline Conventos & $\begin{array}{c}\text { Enfermos que } \\
\text { entraron }\end{array}$ & Fallecidos & \% Fallecidos & Religiosos & $\begin{array}{c}\text { media anual } \\
\text { de enfermos } \\
\text { por religioso }\end{array}$ & $\begin{array}{c}\text { Propuesta de } \\
\text { Asignación de } \\
\text { Religiosos }\end{array}$ \\
\hline Panamá & 6011 & 436 & 7,25 & 9 & 95,41 & 12 \\
\hline Cartagena & 12325 & 555 & 4,50 & 23 & 89,31 & 24 \\
\hline Santafé & 9766 & 1111 & 11,37 & 41 & 34,02 & 30 \\
\hline Portobelo & 4327 & 155 & 3,58 & 3 & 240,38 & 6 \\
\hline Natá & 349 & 76 & 21,77 & 3 & 16,61 & 4 \\
\hline Mompóx & 597 & 185 & 19,33 & 3 & 39,80 & 5 \\
\hline Tunja & 954 & 203 & 21,27 & 5 & 38,16 & 6 \\
\hline Pamplona & 321 & 17 & 5,29 & 5 & 12,84 & 5 \\
\hline Vélez & 311 & 131 & 42,12 & 3 & 20,73 & 4 \\
\hline Villa de Leiva & 134 & 36 & 26,86 & 3 & 8,93 & 4 \\
\hline Mariquita & 179 & 37 & 20,67 & 3 & 11,93 & 4 \\
\hline Santa Marta & 840 & 56 & 6,66 & 3 & 31,11 & 6 \\
\hline Cali & 94 & 14 & 14,89 & $i ?$ & & ¿? \\
\hline Honda & 1395 & 218 & 15,62 & 3 & 66,42 & 6 \\
\hline Totales & $\mathbf{3 7 9 6 3}$ & $\mathbf{3 2 3 0}$ & $\mathbf{8 , 5 0}$ & $\mathbf{1 0 7}$ & $\mathbf{6 0 , 1 3}$ & $\mathbf{1 2 2}$ \\
\hline
\end{tabular}


número de religiosos es Panamá con 9 personas, pero de ellos solo cuatro cumplen con funciones vinculadas a la asistencia corporal.

Estos sujetos cumplían funciones como: prior, consiliario, presbítero, capellán, sacristán, cantor, corista, organista, enfermero, boticario, refectolero, ropero, cocinero, despensero y demandante. Sin embargo, en la mayoría de estas instituciones el número de Juaninos variaba entre 3 y 5 , los cuales debían suplir las necesidades propias de estas instituciones, no solo con las actividades de tipo médico y terapéutico, sino también las de carácter administrativo, religioso y conventual. No obstante, la nómina de dichos hospitales generalmente se componía de un prior, un enfermero y un consiliario, presbítero o capellán, aunque en algunos casos un religioso debía cumplir varias funciones.

Por otro lado, se puede observar como en la columna de asignación de religiosos, el visitador-reformador general propone una reorganización en la estructura de la nómina de dichos hospitales, idea que responde a una necesidad de minimizar costos y de aprovechar los recursos humanos con los que contaba la Orden religiosa para la atención de los enfermos, pero también velando por la inversión de los recursos que tenía el gobierno español en estos establecimientos.

Aquí es evidente el interés que tiene la Corona en la ejecución de estas visitas-reforma, para poder hacer una reducción en el número de los religiosos que atienden el hospital, y de esta manera fortalecer su posición en la estructura administrativa de estos establecimientos. Por otro lado, de la Concepción y Delgado presenta un cuadro donde Santa Fe, Cartagena y Panamá recibirían el mayor número de religiosos, los cuales no superan los 30 individuos, número que para la cifra real de enfermos no iba a ser suficientes. De hecho los hospitales de Panamá y Cartagena tenían una asignación anual de 95 y 89 enfermos por religioso respectivamente, número que evidenciaba los problemas que había en la atención de pacientes y la carencia de los recursos humanos para satisfacer las necesidades de este sector.

Sin embargo, el caso más llamativo es el de Portobelo, el cual tenía un promedio de 240 enfermos al año quienes eran atendidos por solo tres religiosos. La situación es preocupante si se tiene en cuenta que en ese momento Portobelo era uno de los principales puertos sobre el Atlántico, y punto obligado en la ruta comercial que transportaba mercancías entre el Pacífico y el Caribe. A pesar de esto, en la propuesta hecha por la Concepción y Delgado, se sigue manifestando un número muy bajo de religiosos que difícilmente mejorarían la asistencia de los enfermos en esta ciudad, al igual que en Honda, donde a pesar manifestar un número muchísimo más bajo de enfermos por religioso (66) sigue reproduciendo el mismo modelo de atención. 
A propósito de la cantidad de enfermos que eran atendidos en estos hospitales, son nuevamente Cartagena (32,46\%), Santa Fe (25,72\%), Panamá $(15,83 \%)$, Portobelo $(11,39 \%)$ y Honda $(3,67 \%)$ los poblados con mayor número de personas asistidas. Esto no solamente se relaciona con la proporción de habitantes que había en cada una de estas ciudades, sino también con la naturaleza que definía a cada una, se está hablando de la capital del Virreinato y de los principales puertos marítimos y fluviales de la Nueva Granada. Habría que pensar en toda esa población flotante que frecuentaba estos poblados y que se manifiesta a su vez en la cantidad de enfermos a tratar en los hospitales. Por ejemplo, Cartagena con el 77,95\%, Portobelo con el 76,75\% y Panamá con el $62,15 \%$ fueron las ciudades en las que los soldados del ejército español superaron en gran medida la proporción de enfermos, comparado con el número de pobres que fueron atendidos. Asimismo, se explica la inversión que hizo la Corona española en los hospitales de dichas ciudades, importantes en la defensa de los intereses del gobierno peninsular en América.

A pesar de la difícil situación de la asistencia a los enfermos, se destaca también la proporción de personas fallecidas por número de enfermos ingresados a estas instituciones. Tal vez el caso más llamativo fue el de Vélez, donde el $42,12 \%$ de los pacientes que entraron al hospital murieron, no obstante no hay información que explique este altísimo índice de mortalidad en la población veleña. Los otros establecimientos con mayor número de bajas entre sus pacientes fueron Villa de Leyva $(26,86 \%)$, Natá $(21,77 \%)$ y Tunja $(21,27 \%)$. Por otro lado, los hospitales con menor proporción de fallecidos fueron Portobelo $(3,58 \%)$, Cartagena $(4,50 \%)$ y Pamplona $(5,29 \%)$, donde paradójicamente los hospitales de las primeras dos ciudades tuvieron algunos de los porcentajes más altos para el ingreso de enfermos, lo que muestra que ambas variables (número de enfermos y número de fallecidos) no son directamente proporcionales.

Sin embargo, se resalta que en las visitas-reforma no se hace mención directa al ejercicio de la práctica médica. Esto evidencia por un lado cómo se mantiene la idea de enfermedad y curación en relación con los aspectos espirituales más que con los corporales, pero también muestra la falta de interés en el registro de estas variables, lo que a su vez va a influir en la dificultad de introducir los discursos que desde la ciencia pretendían aplicarse a los hospitales. De hecho, la práctica asistencial en los hospitales hasta el siglo XVIII se concebía como un medio moralizante en el que la enfermedad era empleada como un recurso para lograr la gracia divina ${ }^{41}$.

41 Restrepo Zea, 2006: 82. 
La moral también se insertará en el discurso que define las pautas de los cuerpos saludables, que no implica únicamente una manera de comportarse, sino también el conjunto de sentidos de valores configurados y ejecutados por la sociedad. De esta manera, un cuerpo que es considerado saludable y el sujeto que lo porta, es moral. Esta idea atraviesa todo el paradigma de la salud y de la vida cotidiana en el período colonial, un proceso que abrirá paso posteriormente a la medicalización ${ }^{42}$. En esta lógica se entiende cómo el cuerpo enfermo, el cuerpo pecador, es purificado mediante la oración y los tratamientos que se le ofrecen en el hospital, incluso aquellos que contemplan la muerte, que también era un ámbito cobijado por la Iglesia.

Pero el espacio también va a desempeñar un rol importante, recluyendo al pobre y al enfermo en el hospital se puede moralizar y reformar las costumbres, ocupando a estos sujetos en actividades beneficiosas para la comunidad, que iban desde la elaboración de trabajos manuales, mandaderos, pidiendo limosna o cuidando enfermos, aspectos que se ajustaban muy bien al modelo de los Borbones ${ }^{43}$. Incluso la oración era considerada una actividad de beneficio público, ya que con ella se suplicaba el perdón de los pecados.

Esta situación nos lleva a pensar en otro tipo de aspectos que se deben considerar para evaluar la efectividad que tenían estas instituciones en sus labores de asistencia corporal, donde no solo intervenían los recursos humanos y financieros, sino también aquellos de carácter logístico asociados con la infraestructura, mobiliario, instrumentos y materiales adecuados para prestar los servicios médicos, terapéuticos y religiosos que requerían los enfermos.

\section{INSTALACIONES FÍSICAS Y ORNAMENTOS}

Durante las visitas-reforma, tanto el visitador principal como su secretario y el prior del convento hospital procedían a revisar cada uno de los espacios que componían la iglesia y claustro del establecimiento asistencial, empezando por la visita al Santísimo Sacramento, generalmente después de efectuar su correspondiente celebración litúrgica. Se realizaba posteriormente un inventario de cada una de las salas, teniendo en cuenta lo adecuadas que estaban para las funciones a las que fueron asignadas y si todo el mobiliario y ornamento que poseían estaban de acuerdo con ellas. A continuación se presentan algunos de los aspectos registrados en los hospitales neogranadinos, donde se observa la marcada diferencia en la capacidad que tenían estos espacios, lo

42 Risse, 1999. Foucault, 2003.

43 Alzate Echeverri, 2012: 153-155. 
que sugiere a su vez un contexto diferencial en la cantidad de población que atendían.

TABla 4. CuAdro COMPARATIVO ENTRE los ESPACIOS DE LOS HOSPITALES DE NuEVA GRANADA

\begin{tabular}{|l|l|l|l|l|l|l|l|l|l|l|l|l|l|l|}
\hline \begin{tabular}{|l} 
Espacios que componen los conventos \\
hospitales
\end{tabular} & $\mathbf{1}$ & $\mathbf{2}$ & $\mathbf{3}$ & $\mathbf{4}$ & $\mathbf{5}$ & $\mathbf{6}$ & $\mathbf{7}$ & $\mathbf{8}$ & $\mathbf{9}$ & $\mathbf{1 0}$ & $\mathbf{1 1}$ & $\mathbf{1 2}$ & $\mathbf{1 3}$ & $\mathbf{1 4}$ \\
\hline Santísimo Sacramento y Santo Óleo & $\mathrm{P}$ & $\mathrm{P}$ & $\mathrm{P}$ & $\mathrm{P}$ & $\mathrm{P}$ & $\mathrm{P}$ & $\mathrm{P}$ & $\mathrm{P}$ & $\mathrm{P}$ & $\mathrm{P}$ & $\mathrm{P}$ & $\mathrm{P}$ & $\mathrm{P}$ & $\mathrm{P}$ \\
\hline Altares & $\mathrm{P}$ & $\mathrm{P}$ & $\mathrm{P}$ & $\mathrm{P}$ & $\mathrm{P}$ & $\mathrm{P}$ & $\mathrm{P}$ & $\mathrm{P}$ & $\mathrm{P}$ & $\mathrm{P}$ & $\mathrm{P}$ & $\mathrm{P}$ & $\mathrm{P}$ & $\mathrm{P}$ \\
\hline Altar Mayor & $\mathrm{P}$ & $\mathrm{P}$ & $\mathrm{P}$ & $\mathrm{P}$ & $\mathrm{P}$ & $\mathrm{P}$ & $\mathrm{P}$ & $\mathrm{P}$ & $\mathrm{P}$ & $\mathrm{P}$ & $\mathrm{P}$ & $\mathrm{P}$ & $\mathrm{P}$ & $\mathrm{P}$ \\
\hline Coro y Campanario & $\mathrm{P}$ & $\mathrm{P}$ & $\mathrm{P}$ & & & & $\mathrm{P}$ & $\mathrm{P}$ & & & $\mathrm{P}$ & & $\mathrm{P}$ & $\mathrm{P}$ \\
\hline Sacristía & $\mathrm{P}$ & $\mathrm{P}$ & $\mathrm{P}$ & $\mathrm{P}$ & $\mathrm{P}$ & $\mathrm{P}$ & $\mathrm{P}$ & $\mathrm{P}$ & $\mathrm{P}$ & $\mathrm{P}$ & $\mathrm{P}$ & $\mathrm{P}$ & $\mathrm{P}$ & $\mathrm{P}$ \\
\hline Celdas de los religiosos & $\mathrm{P}$ & $\mathrm{P}$ & $\mathrm{P}$ & $\mathrm{P}$ & $\mathrm{P}$ & $\mathrm{P}$ & $\mathrm{P}$ & $\mathrm{P}$ & $\mathrm{P}$ & $\mathrm{P}$ & $\mathrm{P}$ & $\mathrm{P}$ & $\mathrm{P}$ & $\mathrm{P}$ \\
\hline Noviciado & $\mathrm{P}$ & $\mathrm{P}$ & $\mathrm{P}$ & & & & & & & & & & & \\
\hline Enfermería de Hombres & $\mathrm{P}$ & $\mathrm{P}$ & $\mathrm{P}$ & $\mathrm{P}$ & $\mathrm{P}$ & $\mathrm{P}$ & $\mathrm{P}$ & $\mathrm{P}$ & $\mathrm{P}$ & $\mathrm{P}$ & $\mathrm{P}$ & $\mathrm{P}$ & $\mathrm{P}$ & $\mathrm{P}$ \\
\hline Enfermería de Mujeres & $\mathrm{P}$ & $\mathrm{P}$ & $\mathrm{P}$ & & & & $\mathrm{P}$ & $\mathrm{P}$ & & $\mathrm{O}$ & & & $\mathrm{P}$ & \\
\hline Ropería & $\mathrm{P}$ & $\mathrm{P}$ & $\mathrm{P}$ & $\mathrm{P}$ & $\mathrm{P}$ & $\mathrm{P}$ & $\mathrm{P}$ & $\mathrm{P}$ & $\mathrm{P}$ & & $\mathrm{P}$ & $\mathrm{P}$ & $\mathrm{P}$ & $\mathrm{P}$ \\
\hline Botica & $\mathrm{P}$ & $\mathrm{P}$ & $\mathrm{P}$ & $\mathrm{P}$ & & $\mathrm{P}$ & $\mathrm{P}$ & $\mathrm{P}$ & & & $\mathrm{P}$ & & $\mathrm{P}$ & $\mathrm{P}$ \\
\hline Despensa y Cocina & $\mathrm{P}$ & $\mathrm{P}$ & $\mathrm{P}$ & $\mathrm{P}$ & $\mathrm{P}$ & $\mathrm{P}$ & $\mathrm{P}$ & $\mathrm{P}$ & $\mathrm{P}$ & $\mathrm{P}$ & $\mathrm{P}$ & $\mathrm{P}$ & $\mathrm{P}$ & $\mathrm{P}$ \\
\hline Refectorio & $\mathrm{P}$ & $\mathrm{P}$ & $\mathrm{P}$ & $\mathrm{P}$ & $\mathrm{P}$ & $\mathrm{P}$ & $\mathrm{P}$ & $\mathrm{P}$ & $\mathrm{P}$ & $\mathrm{O}$ & $\mathrm{P}$ & $\mathrm{P}$ & $\mathrm{P}$ & $\mathrm{P}$ \\
\hline Campo Santo & $\mathrm{P}$ & $\mathrm{P}$ & $\mathrm{P}$ & $\mathrm{P}$ & $\mathrm{P}$ & $\mathrm{P}$ & $\mathrm{P}$ & $\mathrm{P}$ & $\mathrm{P}$ & $\mathrm{P}$ & $\mathrm{P}$ & $\mathrm{P}$ & $\mathrm{P}$ & $\mathrm{P}$ \\
\hline Puertas y Cerca & $\mathrm{P}$ & $\mathrm{P}$ & $\mathrm{P}$ & $\mathrm{P}$ & $\mathrm{P}$ & & $\mathrm{P}$ & $\mathrm{P}$ & $\mathrm{P}$ & $\mathrm{P}$ & & & $\mathrm{P}$ & \\
\hline
\end{tabular}

1: Panamá. 2: Cartagena. 3: Santa Fe. 4: Portobelo. 5: Natá. 6: Mompox.7: Tunja. 8: Pamplona. 9: Vélez. 10: Villa Leyva. 11: Mariquita. 12: Santa Marta. 13: Cali. 14: Honda. P: Presente. O: En Obra.

Como se ve en la tabla 4, todos los hospitales poseen espacios adecuados para las prácticas religiosas, tienen construida una iglesia donde ofrecen los servicios litúrgicos destinados al público en general y donde depositan los elementos empleados en las misas y la administración de los sacramentos, particularmente el santísimo sacramento y el santo óleo, los cuales son suministrados durante la comunión y la unción de los enfermos respectivamente. No obstante, en 6 de los 14 hospitales el santo óleo era depositado en sitios diferentes al templo del hospital, por ejemplo en Mariquita se resguarda en la sacristía, mientras que en Panamá, Santa Fe, Portobelo, Santa Marta y Mompóx, se encuentra ubicado en las enfermerías, situación que puede ser expli- 
cada por la cantidad de enfermos que tenían, sobre todo en las primeras tres, donde les era más práctico a los religiosos resguardarlo allí para administrar este aceite a sus pacientes.

Por otro lado, se encuentra la sacristía, espacio por lo general anexo a las iglesias y donde guardaban las ropas, ornamentos y libros vinculados con el ejercicio litúrgico. En todos los hospitales se encuentra este espacio, lo que no sucede con el coro y el campanario, los cuales están ausentes en los establecimientos de Natá, Mompóx, Vélez, Villa de Leyva, Santa Marta y Portobelo. En el caso de los primeros 4 hospitales esto puede asociarse con los bajos ingresos en sus arcas y a la baja densidad de población enferma que atendían, lo que no significaba una prioridad el hecho de convocar a misa a la población circundante del convento. Otra situación es la que viven Santa Marta y Portobelo, ya que reciben una buena cantidad de recursos y atendían un importante número de enfermos, por lo que no queda claro la ausencia del registro de este espacio en sus respectivas visitas-reforma. Otro de los espacios que está presente en todos los establecimientos hospitalarios son las celdas de los religiosos, las cuales no tienen muchas diferencias entre sí, a excepción de la que pertenecía al Prior, ya que allí era donde se guardaba el archivo de depósito y las escrituras a nombre del hospital, el cual era protegido con tres llaves que estaban en posesión de las cabezas administrativas de cada institución. De igual forma, solo los hospitales de Santa Fe, Cartagena y Panamá estaban habilitados para la formación de los novicios que engrosarían la nómina de religiosos de esta orden. No obstante, a raíz de la visita hecha por de la Concepción y Delgado se determinó que el hospital de Tunja pasaría a ser noviciado en lugar del de Panamá argumentándolo de la siguiente forma:

... en el Convento Hospital de la ciudad de Panamá de muchos años a esta parte, no ha habido quien se incline a tomar el santo hábito, queda señalado en su lugar por casa de noviciado el Convento Hospital de la ciudad de Tunja, con lo que se verifica quedar completas las tres casas de noviciado, que hasta de presente ha habido en esta santa provincia como son esta de Santafé, la de Cartagena y dicha de Tunja ${ }^{44}$.

Las dificultades para convocar nuevos novicios, acentúa la situación observada en la proporción de enfermos por religioso. Al respecto, influyeron no solo los inconvenientes financieros, sino también el origen de estos hom-

44 Testimonio de la visita practicada en el hospital de Tunja, por Fray Nicolás de la Concepción Delgado, en su carácter de visitador de los religiosos de San Juan de Dios de Nueva Granada, Tunja, septiembre de 1776, AGN, Conventos 39, ff. 906r-906v. 
bres que en algún momento decidieron tomar el hábito y asistir a los pobres enfermos. Muchos de ellos resultaban a veces marginales por sus dudosas raíces, situación frecuente en España, que pudo flexibilizarse en América con el ingreso de hijos ilegítimos, mestizos y personas con un bajo nivel de conocimientos que afectaron el funcionamiento de los hospitales ${ }^{45}$. Por otro lado, habría que considerar si un cambio en los intereses de carácter material pudo haber influido en la imagen del sacerdote como figura respetada, así como se vio en la disminución de las limosnas hechas a la iglesia por particulares en beneficio de legar los bienes a sus deudos, se pudo haber trasladado esa dinámica al contexto ideológico y ocupacional.

Por otro lado, hubo que hacer una serie de adecuaciones en la infraestructura de los hospitales para que pudieran ser aptas para la asistencia de los enfermos. Al respecto, algunos de los establecimientos no tenían una separación clara para la atención de los pacientes en dichas instituciones. Por ejemplo, en Mariquita, Santa Marta, Honda y Villa de Leyva el visitador general considera prioritario separar los enfermos por sexos, ya que al momento de su visita se encontraron mezclados hombres y mujeres en una misma sala, aconsejando la construcción y finalización de las enfermerías destinadas para individuos femeninos. Por otro lado, no hay claridad en la distribución de las salas de atención en los hospitales de Vélez, Mompóx, Natá, Portobelo y Panamá. Para los dos últimos se indica la existencia de salas de enfermería exclusivas para la atención de soldados, además de las de los pobres, que tal vez agrupaban tanto a hombres como a mujeres.

Hubo además otras instalaciones que respondían a la alimentación, convalecencia, prácticas terapéuticas y funerarias. Pese a ello, hubo en algunos hospitales la ausencia de oficinas destinadas a estos menesteres, como la ropería de Villa de Leyva o la Botica en los hospitales de Natá, Vélez, Villa de Leyva y Santa Marta, lo que pudo haber incrementado los gastos relacionados con la adquisición de los medicamentos necesarios en la atención de los enfermos.

Es claro que los problemas señalados en la infraestructura espacial de los establecimientos asistenciales en la Nueva Granada tienen una relación directa con los aspectos financieros de los hospitales, los cuales estuvieron marcados por el déficit presupuestal que a su vez influyó en la calidad, tipo de atención y cuidados que recibieron los pobres enfermos, los cuales muchas veces se vieron desplazados por satisfacer los intereses de otros sujetos involucrados en la dinámica de estas instituciones. Solo por mencionar un ejemplo, en los hospitales donde se atendían soldados o miembros de la armada espa-

45 Alberro, 2005: 247. 
ñola (Cartagena, Portobelo y Panamá), se ve un mayor esmero en la atención de estos individuos en comparación con los pobres, lo que también genera una relación directa con las prioridades de la Corona española y expresa una de las principales misiones que tenían estos hospitales bajo su patronato en ultramar.

\section{CONSIDERACIONES FINALES}

A pesar de que las fuentes documentales no brindan información sobre la efectividad que tuvo la ejecución de las visitas-reforma, dentro del programa reformista elaborado por la casa de los Borbones, es importante señalar como se adecúa y se aprovecha esta herramienta en favor de los intereses de la Corona española.

La necesidad de conocer cuáles eran las inversiones y los capitales que el gobierno peninsular tenía en sus colonias, además de identificar cómo era la dinámica de su funcionamiento, generó que las visitas-reforma constituyeran un elemento clave en el proceso de registro, clasificación y ordenamiento de aquellos aspectos que le eran útiles a España, procesos que fueron extendidos a otras áreas. De esta forma, los estamentos institucionales tendrían los elementos suficientes para irse apropiando de los saberes y en este caso, de los mecanismos de control para emplearlos según sus intereses. Asimismo, esto se relaciona con el proyecto civilizador que atravesará todas las esferas de la cotidianidad.

Los hospitales como instituciones entrarían a formar parte de esa red de registro y control, sin embargo no pierden el carácter religioso con el que se han vinculado desde su llegada a América, razón por la cual se dan otro tipo de matices al objetivo inicial de la Corona española frente al uso de las visitas-reforma. De hecho la impronta de lo religioso se manifiesta incluso en la manera en que son ejecutados estos mecanismos de registro, los cuales reciben la influencia de una sociedad sacralizada, construida a lo largo del período de conquista y colonia, que se mantiene a pesar de los nuevos discursos que empiezan a introducirse.

Por otro lado, la dependencia económica del Real Patronato que se manifiesta en las rentas de los establecimientos asistenciales en el Nuevo Mundo, condicionará a dichas instituciones para satisfacer las necesidades que tiene el gobierno peninsular frente a la atención hospitalaria de algunos sectores poblacionales, importantes en la ejecución de sus políticas administrativas, como es el caso de los soldados y los miembros de la marina. 
No obstante, es evidente la insostenibilidad económica y logística que caracterizaba estos hospitales y más cuando las entradas por limosna empezaron a disminuir de manera considerable, lo que obviamente afectó en otras áreas de actividad de estas instituciones, incluyendo la atención que recibían los enfermos y las condiciones infraestructurales de estos espacios. Precisamente, a estos dos aspectos son a los que menor importancia le dan las autoridades civiles en sus lecturas de las visitas-reforma, en las que evidentemente hay un objetivo claramente económico, que concentra su atención especialmente en los asuntos financieros, con el ánimo de minimizar y justificar los gastos de la corona en estos establecimientos. En este sentido los hospitales neogranadinos de la segunda mitad del siglo XVIII distan mucho de ser espacios para la cura de enfermedades y mucho menos para el ejercicio de la medicina. Seguían siendo ante todo edificios religiosos que no lograban articularse con los intereses económicos de la Corona. Quizá solo el hospital de Santafé logra integrarse a la academia cuando se convierte en departamento anexo de la facultad de Medicina en 1801, formando a los futuros médicos de la ciudad ${ }^{46}$.

Asimismo, se empiezan a generar discusiones en relación al manejo de los dineros y a cuestionar el comportamiento de los religiosos frente a sus obligaciones conventuales y asistenciales, señalamientos que son usados para justificar la disminución y reorganización de la nómina de Juaninos en cada hospital, pero como se mencionó arriba no hay evidencia de las implicaciones $\mathrm{y}$ de las medidas que se tomaron al respecto.

Esto lleva a pensar que las visitas-reforma se convirtieron en herramientas de registro y de descripción, que pudieron haber generado un importante cuerpo de datos sobre los que se discutió y con los que se diseñaron estrategias de mejora acordes con los propósitos de la Corona. Sin embargo fue difícil la implementación de los mismos y en algunos casos no se lograron cambios significativos en las décadas siguientes. Al respecto, Plata ${ }^{47}$ aborda cómo el proyecto de las reformas borbónicas, que tenía entre sus principales objetivos la secularización de las doctrinas; fracasó por la dificultad en el ejercicio de las medidas gubernamentales y en las respuestas que generó dentro del ámbito eclesiástico.

En este caso en específico, vemos que hay una ausencia de los discursos institucionales de la ciencia y la medicina, lo que muestra una clara ruptura en los intereses que tenía el gobierno peninsular y los instrumentos que fueron usados posteriormente para la introducción e incorporación de dichos discur-

\footnotetext{
46 Martínez Zulaica, 1973: 172.

47 Plata, 2009: 285.
} 
sos. Teniendo en cuenta esto, habría que preguntarse en qué medida fueron ejecutadas otras disposiciones estatales, la efectividad que eventualmente pudieron haber tenido y en qué contextos particulares fueron aplicadas.

Finalmente, es importante resaltar la riqueza informativa que proporciona este tipo de registros dada su naturaleza descriptiva, en la que además de la minucia que se observa en su producción, se aborda una multiplicidad de variables que hacen parte de la vida cotidiana de estos conventos hospitales. Son estos los aspectos en los que habría que profundizar para ampliar el conocimiento que se tiene sobre las dinámicas propias de estos centros asistenciales, insertos en la cotidianidad de los poblados hispanoamericanos.

\section{BIBLIOGRAFÍA}

Agudelo, Benjamín OH, Los Hijos del San Juan de Dios en Nueva Granada, Colombia, Bogotá, Carvajal S.A., 1983.

Albarracín Teulán, Agustín, "La medicina española de los siglos XVI, XVII, XVIII y su influencia en Colombia", Cuadernos Hispanoamericanos, 472 (Madrid, 1989): 31-34.

Alberro, Solange, Apuntes para la historia de la Orden Hospitalaria de San Juan de Dios en la Nueva España-México, 1604-2004, México, El Colegio de México/ Orden Hospitalaria de San Juan de Dios, 2005.

Alzate Echeverri, Adriana María, "Devociones políticas y oratoria salubrista. Sobre un plan de reforma hospitalaria en la Nueva Granada (1790)", Historia Crítica, 23 (Bogotá, 2002): 51-68.

Alzate Echeverri, Adriana María, Suciedad y Orden. Reformas sanitarias borbónicas en la Nueva Granada 1760-1810, Bogotá, Instituto Colombiano de Antropología e Historia/Universidad de Antioquia/Universidad del Rosario, 2007.

Alzate Echeverri, Adriana María, Geografia de la lamentación. Institución hospitalaria y sociedad Nuevo Reino de Granada, 1760-1810, Bogotá, Editorial Pontificia Universidad Javeriana/Universidad del Rosario, 2012.

Amaya, José Antonio, Mutis, apóstol de Linneo: historia de la botánica en el virreinato de la Nueva Granada (1760-1783), Bogotá, Instituto Colombiano de Antropología e Historia, 2005.

Amaya, José Antonio y Torres Moreno, James Vladimir, "La Expedición Botánica a la luz de las cifras, 1783-1816", Olga Restrepo Forero (ed.), Proyecto ensamblando en Colombia, Bogotá, Universidad Nacional de Colombia, 2013: 41-75. 
Andrade González, Gerardo, "Mutis y la política estatal neogranadina sobre la investigación científica", Javier Guerrero (comp.), Medicina y Salud en la historia de Colombia, Bogotá, Universidad Pedagógica y Tecnológica de Colombia/Archivo General de la Nación, 1997: 91-95.

Barrancos, Dora, La Escena iluminada. Ciencia para trabajadores (1890-1930), Buenos Aires, Plus Ultra, 1996.

Cruz-Coke Madrid, Ricardo, Historia de la Medicina Chilena, Santiago, Editorial Andrés Bello, 1995.

Díaz Piedrahita, Santiago, "La Real Expedición Botánica y el movimiento de emancipación”, Credencial Historia, 240 (Bogotá, 2009): 7-12.

Foucault, Michel, La vida de los hombres infames, La Plata, Editorial Altamira, 1996.

Foucault, Michel, El Nacimiento de la Clínica: una Arqueología de la mirada médica, Buenos Aires, Siglo Veintiuno Editores, 2003.

Frías Núñez, Marcelo, Enfermedad y sociedad en la crisis colonial del antiguo régimen: Nueva Granada en el tránsito del siglo XVIII al XIX, las epidemias de viruela, Madrid, CSIC, 1992.

Frías Núñez, Marcelo, Tras El Dorado vegetal: José Celestino Mutis y la Real Expedición Botánica del Nuevo Reino de Granada, Sevilla, Diputación Provincial de Sevilla, 1994.

Gélis, Jacques, "El cuerpo, la Iglesia y lo sagrado", Alain Corbin, Jean Jacques Courtine y Georges Vigarello (eds.), Historia del Cuerpo. Volumen 1: Del Renacimiento al siglo de las luces, Madrid, Taurus, 2005: 27-111.

Guerra, Francisco, El Hospital en Hispanoamérica y Filipinas 1492-1848, Madrid, Ministerio de Sanidad y Consumo, Secretaria de Estado para la Cooperación Internacional, 1994.

Hernández de Alba, Guillermo, Historia documental de la Real Expedición Botánica del Nuevo Reino de Granada, Bogotá, Instituto colombiano de Cultura Hispánica, 1986.

López Piñero, José María, Medicina e Historia Natural en la sociedad española de los siglos XVI y XVII, Valencia, Universitat de Valencia, 2007.

Lynch, John, La España del siglo XVIII, Barcelona, Crítica, 2009.

Martínez Zulaica, Antonio, La medicina del siglo XVIII en el Nuevo Reino de Granada, Tunja, Universidad Pedagógica y Tecnológica de Colombia, 1973.

Nieto Olarte, Mauricio, Remedios para el Imperio. Historia natural y la apropiación del nuevo mundo, Bogotá, Instituto Colombiano de Antropología e Historia, 2000. 
Ortiz Quesada, Federico, Hospitales, México, McGraw-Hill Interamericana, 2000. Pérez Arbeláez, Enrique, José Celestino Mutis y la Real Expedición Botánica de la Nueva Granada, Bogotá, Instituto Colombiano de Cultura Hispánica, 1983.

Plata, William Elvis, "Un acercamiento a la participación del clero en la lucha por la independencia de Santafé y la Nueva Granada: el caso de los dominicos (17501815)", Fronteras de la Historia, 14/2 (Bogotá, 2009): 282-313.

Restrepo Zea, Estela, "El Hospital San Juan de Dios 1635-1900", Recetas para el espíritu para enfermos del cuerpo, Bogotá, Universidad Nacional de Colombia, 2006: 47-102.

Risse, Guenter B., Mending bodies, saving souls. A history of hospitals, Oxford, Oxford University Press, 1999.

Rivera Sandoval, Javier, Costumbres Funerarias en la Cartagena Colonial Siglos XVI-XVIII. Estudio en el Claustro de Santo Domingo, Bogotá, Departamento de Antropología, Universidad Nacional de Colombia (tesis inédita), 2004.

Rivera Sandoval, Javier, "Curando corpos e Salvando Almas. O Tratamento Corporal no Hospital São João de Deus do Panamá Velho", Flavia Regina Marquetti y Pedro Paulo A. Funari (eds.), Corpo a corpo. Representações antigas e modernas da figura humana, Sao Paulo, Editora FAP-UNIFESP, 2014: 185-218.

Romero, Arturo, La investigación de las dolencias infecciosas en la Historia, Bogotá, Academia Colombiana de Ciencias Exactas, Físicas y Naturales, 1997.

San Pio Aladrén, María Pilar, Mutis y la Real Expedición Botánica del Nuevo Reyno de Granada, Madrid, CSIC, Real Jardín Botánico, 2008.

Solano Alonso, Jairo, El arte de curar en el Caribe colombiano. Del chamán al Médico, Barranquilla, Corporación educativa Simón Bolívar, 2005.

Fecha de recepción: 1 de octubre de 2015.

Fecha de aceptación: 13 de abril de 2016. 


\section{A look at hospitals of the San Juan de Dios Order in New Granada following the reformation-visits (1774-1777)}

In the second half of the eighteenth century, the financial, administrative and health care crisis of the colonial hospitals became apparent. As part of the policy to improve and control operations financed by the Spanish Crown, search mechanisms were implemented to evaluate the situation of these centres. This paper covers the documentary series produced between 1774 and 1777 by Fray Nicolas de la Concepción Delgado, visitor of fourteen hospitals of the San Juan de Dios order in New Granada, present-day Colombia and Panama. Its main objective is to provide information about the circumstances of these institutions based on descriptions made in the visitas-reforma or reformation-visits, and the relevance for Spain's peninsular government of the search and inventory conducted on aspects of the hospitals economic and social life.

KeY-words: hospitals; New Granada; eighteenth century; visitas-reforma; Colombia; Panama 